that Su: searches target references from the title, subject, and series field results in retrieving irrelevant records. Further, end users do not have access to thesaurus and subject headings lists and therefore would expect the word list to be much more comprehensive. The online help screens need to be transparent to users for important search concepts. End users should be provided with one definitive method of searching a field which would result in retrieval of relevant references.

\section{Conclusion}

FirstSearch offers an inexpensive and attractive service. It has very good potential as an end-user resource but attention needs to be directed towards improving the searching characteristics and its method of viewing/printing/ downloading. With the availability of WorldCat, BIOSIS/FS, and the Wilson databases at a very affordable pricing policy, together with location symbols to aid in document delivery, this service could very well be the answer to many of our patrons' information problems.

1"Why Use DB23 on EPIC When We Have LC MARC?" OCLC Reference News (January/February 1992): p. 7

${ }^{2}$ Lutishoor Salisbury and Usha Gupta, FirstSearch: Potential and Search Characteristics (Submitted for publication, 1992), p. 3.

${ }^{3}$ Dialog Database Catalog 1991, p. 40.

\title{
UC tries Firstsearch
}

OCLC offered free public access to its FirstSearch service to the Davis, Irvine, Los Angeles, and San Diego campuses of the University of California (UC) during February 1992. FirstSearch was made available to library users without additional equipment by providing an INTERNET connection to FirstSearch via the MELVYL Library System. The ten-year-old MELVYL is a shared UC information system and includes the nine-campus union catalog, six article databases, and automatic INTERNET connections to about 30 library information systems worldwide.

Starting the second week of February, public access was offered to the four campuses as a menu choice through the UC MELVYL Library System. Remote or modem access was provided to selected users and OCLC provided stacks of coupons, good for ten searches, to distribute to UC users who wanted to have dial-up access from homes, offices, or dormitory rooms.

Librarians from the four campuses held a brief meeting on April 1 and shared the following observations. Although the librarians were concerned that one month was not sufficient time to evaluate a multiple database system such as FirstSearch, users were enthusiastic. They liked the menu-driven system with excellent help screens; most people were able to find something on the first try. Some faculty found the menu-driven system frustrating and were annoyed with the software barrier that prohibits the continuous printing or downloading of records. Connections were not always stable and during peak loads remote users reported being frequently dropped. There was little or no impact on staff at public service desks. The staff liked the ability to control which databases are available to users. For example, if ERIC was available in the library as a CDROM, access to ERIC FirstSearch could be blocked.

During the February trial period 8,099 searches were performed on the 14 databases on FirstSearch, as compared to 1,564,274 MELVYL catalog searches. WorldCat was the most frequently selected database with 3,511 searches. Some librarians thought this was because WorldCat was the first choice on the menu in all the subject categories. The article databases were searched 4,588 times and all files showed some use. Among the article databases, BIOSIS was the most popular followed by News, Humanities Index, Periodical Abstracts, and PAIS.

FirstSearch was a success and worth consideration for librarians who are looking for ways to increase access to the journal literature without local tapeloading.-James E. Crooks, data services coordinator, University of California, Irvine; bitnet: JECROOKS@UCI 